\title{
Ruminal degradation of quercetin and its influence on fermentation in ruminants
}

\author{
L. M. Berger, ${ }^{*}$ R. Blank, ${ }^{* 1}$ F. Zorn, ${ }^{*}$ S. Wein, ${ }^{*}$ C. C. Metges, $†$ and S. Wolffram ${ }^{*}$ \\ *Institute of Animal Nutrition and Physiology, Christian-Albrechts-University of Kiel, 24118 Kiel, Germany \\ †Institute of Nutritional Physiology, Leibniz Institute for Farm Animal Biology, 18196 Dummerstorf, Germany
}

\begin{abstract}
The aim of the present study was to investigate the ruminal degradation of the flavonol quercetin and to determine its potential antimicrobial effects on ruminal fermentation in cows. Ruminal degradation of quercetin (0 or $100 \mu \mathrm{mol} / \mathrm{L}$, respectively) as well as its influence on ruminal gas production $(0,50$, or 100 $\mu \mathrm{mol}$ of quercetin equivalents/L, respectively, either applied as aglycone or as its glucorhamnoside rutin) using concentrate, grass hay, and straw as substrates were investigated in vitro using the Hohenheim gas test. Additionally, the influence of quercetin on ruminal concentrations of volatile fatty acids and their molar ratio in rumen-fistulated, nonlactating cows $(\mathrm{n}=5)$ after intraruminal application of quercetin as aglycone or as rutin $(0,10$, or $50 \mathrm{mg}$ of quercetin equivalents/ $\mathrm{kg}$ of BW, respectively) was evaluated. Quercetin was rapidly and extensively degraded, whereby the disappearance of quercetin was accompanied by the simultaneous appearance of 2 metabolites 3,4-dihydroxyphenylacetic acid and 4-methylcatechol. In vitro total gas and methane production were not reduced by the addition of quercetin aglycone or rutin, respectively, using concentrate, grass hay, and straw as substrates. As expected, however, effects of the substrates used were detected on total gas and methane production. Highest gas production was found with concentrate, whereas values obtained with grass hay and straw were lower. Relative methane production was highest with grass hay compared with concentrate and straw (27.1 vs. 25.0 and $25.5 \%$ ). After intraruminal application of the quercetin aglycone or rutin, respectively, neither total concentration nor the molar ratio of volatile fatty acids in the rumen fluid were influenced. Results of the present study show that quercetin underlies rapid ruminal degradation, whereby 3,4-dihydroxyphenylacetic acid and 4-methylcatechol are the main metabolites, whereas the latter one most likely is formed by
\end{abstract}

Received March 26, 2015.

Accepted April 27, 2015.

${ }^{1}$ Corresponding author: blank@aninut.uni-kiel.de dehydroxylation from 3,4-dihydroxyphenylacetic acid. Regarding antimicrobial effects of quercetin, results obtained indicate that fermentation processes in the forestomachs are not substantially influenced by quercetin or rutin, respectively. With regard to potential health-promoting effects of quercetin, its application in cows, especially in the form of the better available rutin, might not be accompanied by negative effects on ruminal fermentation.

Key words: antimicrobial, cow, Hohenheim gas test, quercetin, ruminal fermentation

\section{INTRODUCTION}

Flavonoids are secondary plant metabolites and ubiquitously present in feed plants of livestock (Besle et al., 2010; USDA, 2011). Among the various flavonoids, the flavonol quercetin (Figure 1) is one of the most investigated polyphenols exhibiting various health-promoting properties; for example, antioxidative, antiinflammatory, and metabolic effects (Middleton et al., 2000; Erlund, 2004). Although those findings mainly derive from in vitro studies or from studies in monogastric species, effects in ruminants such as cows are feasible. In fact, we recently have reported reduced levels of markers of liver damage in periparturient cows (Stoldt et al., 2015). Thus, quercetin might have positive effects on health especially during the stressful phase of early lactation, which is often accompanied by metabolic disorders such as fatty liver and ketoacidosis (Kehrli et al., 2006). In plants, quercetin is mainly present in form of glycosides, e.g., the glucorhamnoside rutin (Figure 1), which for example occurs in significant quantities in buckwheat. Although not commonly used as a feed plant, buckwheat might be used as natural source for quercetin in cows (Broudiscou et al., 2000; Amelchanka et al., 2010). Quercetin content in usual feed for ruminants has not been extensively investigated until now. Few data available indicate amounts of total polyphenols in grass $(35.3 \mathrm{~g} / \mathrm{kg}$ of $\mathrm{DM})$ and maize silage $(3.2$ $\mathrm{g} / \mathrm{kg}$ of DM), respectively (Besle et al., 2010). For cows kept on permanent pastures with polyphenol concentrations ranging between 19 and $32 \mathrm{~g} / \mathrm{kg}$ of DM, Fraisse 

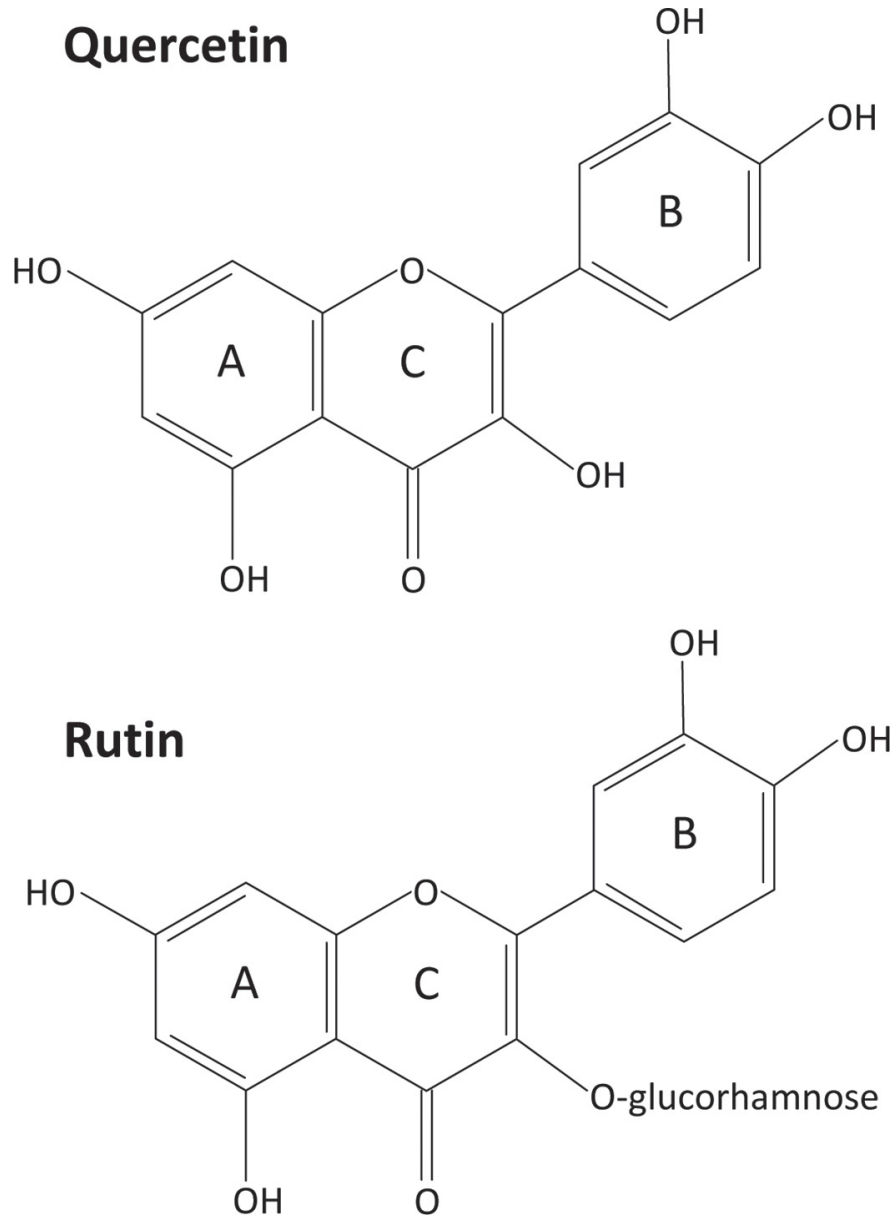

Figure 1. Structure of quercetin and its glucorhamnoside rutin, where $\mathrm{A}, \mathrm{B}$, and $\mathrm{C}$ are the ring structures of flavonols.

et al. (2007) assumed a daily intake of polyphenols of $500 \mathrm{~g} / \mathrm{d}$. Although flavonols including quercetin represent only a fraction of total polyphenols, the amounts consumed by ruminants with their natural feed might well be associated with biological effects.

The systemic availability of a substance is a prerequisite for any postabsorptive effect in vivo. Whereas the bioavailability of quercetin has been extensively investigated in monogastric species (Cermak et al., 2003; Chen et al., 2005; Wein and Wolffram, 2013), only few studies in cows have been performed (Berger et al., 2012; Gohlke et al., 2013). Absolute bioavailability of quercetin after intraruminal (i.r.) application of quercetin either as aglycone or as rutin was low (Berger et al., 2012). Nevertheless, maximal plasma concentrations after rutin application were similar to those obtained in monogastric species after application of equimolar amounts of quercetin aglycone (Cermak et al., 2003). Most interesting, rutin was a much better source of quercetin compared with quercetin aglycone when applied intraruminally (Berger et al., 2012), whereas intraduodenal application of both quercetin sources yielded results as in monogastric species (Gohlke et al., 2013). In monogastric species, quercetin bioavailability from rutin is inferior to that of quercetin aglycone (Cermak et al., 2003). A crucial point regarding the oral bioavailability of a compound is its fate within the gastrointestinal tract. In ruminants, quercetin is expected to undergo intensive microbial fermentation within the forestomachs. Several studies investigated the microbial degradation of quercetin and its glycosides using ruminal and fecal inocula in vitro (Cheng et al., 1969; Krishnamurty et al., 1970; Lin et al., 2003; Labib et al., 2004). Based on those findings, an extensive microbial degradation of quercetin can be assumed, accompanied by the appearance of its degradation products 3,4-dihydroxyphenylacetic acid (3,4-DHPAA); phloroglucinol (PG); and some minor metabolites identified in humans, cows, and pigs (Aura et al., 2002; Labib et al., 2004; Rechner et al., 2004).

Despite the promising health-promoting properties of quercetin, it has to be kept in mind that quercetin might also reveal some negative effects in ruminants due to its antimicrobial effects. Thus, quercetin might negatively influence fermentation processes in the forestomachs and in turn feed efficiency and animal performance. Hence, application of quercetin in ruminants would only be acceptable if positive effects dominate possible negative effects. Several in vitro studies have already investigated the influence of quercetin or quercetincontaining plant extracts, respectively, on microbial fermentation (Broudiscou et al., 2000, 2002; Bodas et al., 2008; Leiber et al., 2012). Those studies, however, yielded inconsistent results.

In the present study, we investigated ruminal degradation of quercetin in vitro. Beside the disappearance of quercetin over time, we also have monitored appearance of its degradation products 3,4-DHPAA, PG, and 4-methylcatechol (4-MC). To gather information on effects of quercetin on fermentation processes, we applied quercetin either as aglycone or as rutin to determine in vitro total gas as well as methane production using the Hohenheim gas test (HGT) together with various substrates (concentrate, grass hay, and straw). In addition, we investigated the influence of quercetin (as aglycone and as rutin, respectively) on concentrations and molar ratios of VFA in vivo after i.r. application in cows.

\section{MATERIALS AND METHODS}

\section{Experimental Design}

All animal experiments were approved by the Ministry of Agriculture, Environment and Rural Areas of 
the federal state Schleswig-Holstein, Germany (No. 127 V312-72241.121-25) and were in accordance with the guidelines issued by the German authorities for care and treatments of animals (Lorz and Metzger, 2008). For experiments 5 ruminally fistulated, nonlactating cows (Deutsches Schwarzbuntes Niederungsrind), age $6 \mathrm{yr}$ with an average BW of $479 \pm 15 \mathrm{~kg}$, were used.

\section{Experiment 1: Ruminal Degradation of Quercetin}

The HGT (Menke and Steingass, 1988) was used to assess the in vitro degradation of quercetin. For the experiment, a substrate consisting of concentrate and grass hay (50:50, wt:wt fresh weight; Table 1) fortified with 0 or $100 \mu \mathrm{mol}$ of quercetin equivalents/L, respectively, as quercetin aglycone (quercetin dihydrate, $\geq 98 \%$ purity; Carl Roth GmbH, Karlsruhe, Germany) was used. Quercetin-containing samples (200 mg) were weighed into calibrated $100-\mathrm{mL}$ glass syringes with pistons lubricated with Vaseline. Ruminal fluid was collected before the morning feeding from 3 ruminally cannulated, nonlactating cows fed restrictively $3 \mathrm{~kg}$ of grass hay and $3 \mathrm{~kg}$ of concentrate divided into 2 meals (8 a.m. and 4 p.m.). The concentrate fed was composed of (\% as fed) 23.2 rye, 21.0 rapeseed extraction meal, 18.5 corn gluten feed, 15.0 milled barley grain, 12.0 rye bran, 4.5 beet pulp, 4.0 corn, and 1.05 calcium carbonate. Additives per kilogram of concentrate were $7.000 \mathrm{IU}$ of vitamin $\mathrm{A}, 850 \mathrm{IU}$ of vitamin $\mathrm{D}_{3}$, and 7.5 mg of copper. Additionally animals received once a day with the morning feeding $75 \mathrm{~g}$ of mineral premix containing (in \%) 41.6 calcium carbonate, 24.4 sodium chloride, 13.9 calcium-sodium phosphate, 7.2 magnesium oxide, 5.0 sugar cane molasses, and 2.0 monocalcium phosphate. Ruminal fluid was collected into a prewarmed insulated flask, immediately transported to the laboratory, homogenized, and filtered through cheesecloth. Strained ruminal fluid was mixed with a freshly prepared buffered mineral solution (Menke and Steingass, 1988) at the ratio of 1:2. Anaerobic condition of rumen fluid during laboratory handling was maintained by continuous flushing with $\mathrm{CO}_{2}$. The mixture was kept stirred with a magnetic stirrer in a water bath at $39^{\circ} \mathrm{C}$. The mixture of ruminal fluid and buffer $(30$ $\mathrm{mL}$ ) was dispensed into each syringe containing the quercetin-containing substrates. After closing the clips placed on the silicon tubes at the syringe tip, syringes were gently shaken and clips were opened to achieve total gas removal by pushing the piston upward. The clips were closed and the syringes were immediately placed in a rotor inside the incubator $\left(39^{\circ} \mathrm{C}\right)$ with about one rotation per minute. Samples were removed from incubator at $0,0.5,1,1.5,2,2.5,3,4,6,8,12$, and 24
Table 1. Nutrient analysis (\% of DM, unless otherwise noted) of concentrate, grass hay, and straw used in the Hohenheim gas test

\begin{tabular}{lrrr}
\hline Item & \multicolumn{3}{c}{ Grass } \\
Concentrate & hay & Straw \\
\hline $\mathrm{DM}$ & 88.7 & 89.9 & 91.9 \\
Crude ash & 7.8 & 7.5 & 4.7 \\
Ether extract & 4.2 & 1.1 & 1.1 \\
Crude protein & 18.5 & 9.9 & 3.9 \\
$\mathrm{NDF}$ & 34.4 & 70.6 & 85.1 \\
$\mathrm{ADF}$ & 12.9 & 40.4 & 51.7 \\
$\mathrm{NE}_{\mathrm{L}}, \mathrm{MJ} / \mathrm{kg}$ of $\mathrm{DM}$ & 7.5 & 4.2 & 6.7 \\
\hline
\end{tabular}

$\mathrm{h}$, gas was released, the total content of syringes was transferred into 50-mL tubes closed and immediately put on ice to avoid any further microbial activity. Incubations were carried out in 8 runs on different days. For determination of the spontaneous decay of quercetin not caused by microbial processes, 4 additional runs with $100 \mu \mathrm{mol} / \mathrm{L}$ quercetin equivalents were performed. The inoculum used in these runs has been cooked and, thus, was inactivated to avoid any microbial activity. All samples were stored at $-70^{\circ} \mathrm{C}$ until analysis.

\section{Experiment 2: Influence of Quercetin on Gas and Methane Production}

The effect of quercetin on in vitro methane and total gas production was evaluated by means of the HGT. Experimental procedures, feeding of donor animals, and ruminal fluid collection were the same as in experiment 1. In this experiment, concentrate, grass hay, and straw were used as substrates without (control) or with the addition of 50 or $100 \mu \mathrm{mol}$ of quercetin equivalents/L, respectively, either applied as aglycone (quercetin dihydrate; Carl Roth $\mathrm{GmbH}$ ) or as rutin (rutin trihydrate, $\geq 98.5 \%$ purity; Carl Roth $\mathrm{GmbH}$ ) using individual rumen fluid from 3 different animals. These treatment combinations were replicated twice per batch and repeated 3 times over a period of 3 wk. The analyzed chemical compositions of the 3 substrates are shown in Table 1. In addition, 3 incubations without a feed sample, containing only mixture of ruminal fluid and buffer, were run within each batch to correct for intrinsic gas production of ruminal fluid. Parallel incubations of reference standards (grass hay and concentrate) obtained from the Hohenheim University (Hohenheim, Germany), as suggested by Menke et al. (1979), were also included in each run. Cumulative gas production was measured over $24 \mathrm{~h}$. The methane concentration in the fermentation gas was measured with an infrared spectrometer (Methan AGM 10, Firma Sensors Europe, Ratingen, Germany) and methane formation was calculated. Calibration of the infrared spectrometer was 
done using pure nitrogen gas (zero point) and a gas mixture of methane and $\mathrm{CO}_{2}(60: 40)$ as standard.

\section{Experiment 3: Influence of Quercetin on In Vivo Production of VFA}

For this in vivo experiment, cows described above were used in a crossover design with a 2-d wash-out period between each application. Animals were restrictively fed with a ration consisting of $1.5 \mathrm{~kg}$ of concentrate and $1.5 \mathrm{~kg}$ of hay twice daily (at 0800 and $1600 \mathrm{~h}$ ) and had free access to tap water.

After a prefeeding phase of $1 \mathrm{wk}, 10$ and $50 \mathrm{mg}$ of quercetin equivalents $/ \mathrm{kg}$ of $\mathrm{BW}$, respectively, were administered either as aglycone (quercetin dihydrate; Carl Roth $\mathrm{GmbH}$ ) or as its rhamnoglucoside rutin (rutin trihydrate; Carl Roth $\mathrm{GmbH}$ ) via the rumen fistula during morning feeding. Respective amounts of quercetin or rutin were suspended in $500 \mathrm{~mL}$ of physiological saline (B. Braun Melsungen AG, Melsungen, Germany). Saline without any addition was used as a control. Samples of rumen fluid $(50 \mathrm{~mL})$ were drawn 0 , $0.5,1,1.5,2,2.5,3,4,6$, and $8 \mathrm{~h}$ after i.r. application and were immediately put on ice to stop any microbial activity. Afterward samples were centrifuged $(12,035 \times$ $g, 4^{\circ} \mathrm{C}, 20 \mathrm{~min}$ ) and $25 \mathrm{~mL}$ of the supernatant was removed, mixed with $2.5 \mathrm{~mL}$ of formic acid (90\%, Merck KGaA, Darmstadt, Germany), and centrifuged again. The supernatant was frozen at $-80^{\circ} \mathrm{C}$ until analysis.

\section{Feed Analysis}

Proximate analysis of feed samples (DM, ash, ether extract, and CP) was done according to the German Handbook of Agricultural Experimental and Analytical Methods (VDLUFA, 2007). Neutral detergent fiber (assayed with heat-stable amylase and inclusion of sodium sulfite) and ADF are expressed exclusive of residual ash (Mertens, 2002).

\section{Analysis of Quercetin and Its Metabolites}

The concentrations of quercetin and of its microbial metabolites PG, 3,4-DHPAA, and 4-MC were determined in the HGT samples. For analyses, 2 separate approaches were applied, one for analysis of quercetin and one for analysis of the metabolites. Preparation of HGT samples was performed similar to that used for analysis of plasma flavonols (Ader et al., 2000) with some modifications. A sample aliquot $(950 \mu \mathrm{L}$ for quercetin analysis or $1 \mathrm{~mL}$ for analysis of quercetin metabolites, respectively) was treated with $140 \mu \mathrm{L}$ of acetic acid (Rotipuran, 100\%, pro analysi; Sigma Aldrich Chemie GmbH, Taufkirchen, Germany). For quercetin analysis, $50 \mu \mathrm{L}$ of a methanolic stock solution containing kaempferol as an internal standard (1 mol/L; Rotichrom HPLC; Carl Roth GmbH \& Co KG) was additionally added. For precipitation of proteins and extraction of quercetin and its metabolites, $2 \mathrm{~mL}$ of acetone (Rotisolv HPLC; Carl Roth $\mathrm{GmbH} \& \mathrm{Co}$ KG) was added, mixed, and continuously shaken on a horizontal shaker for $20 \mathrm{~min}$ and then centrifuged $\left(11,109 \times g\right.$ at $4^{\circ} \mathrm{C}$ for $\left.45 \mathrm{~min}\right)$. The supernatant was evaporated until dryness was reached (Speed-Vac SPD2010, Thermo Savant Instruments, Holbrook, $\mathrm{NY}$ ). Residues were resolved in $1 \mathrm{~mL}$ of the respective HPLC eluent (see below). Thirty microliters of the final solution was injected by a cooled $\left(4^{\circ} \mathrm{C}\right)$ autosampler (Jasco, Groß-Umstadt, Germany) onto a C-18 Kromasil 100 column $(25 \times 4.6 \mathrm{~mm}$, particle size $5 \mu \mathrm{m}$; Jasco) guarded by a C-18 Inertsil ODS-2 precolumn (Jasco) placed in a column oven at $30^{\circ} \mathrm{C}$. For quercetin analysis, the eluent $(0.8 \mathrm{~mL} / \mathrm{min})$ was composed of $25 \mathrm{mM} \mathrm{NaH} \mathrm{PO}_{4}$ (pH 2.4, Merck KgaA), acetonitrile (Chromasolv, $\geq 99.9 \%$; Sigma Aldrich Chemie GmbH), and methanol (67.5:27:5.5, vol/vol/vol; methanol from J.T. Baker, Deventer, the Netherlands). The eluent (1 $\mathrm{mL} / \mathrm{min}$ ) for analysis of metabolites was composed of acetonitrile (Sigma Aldrich Chemie $\mathrm{GmbH}$ ), nanopure $\mathrm{H}_{2} \mathrm{O}$, and trifluoroacetic acid (Carl Roth $\mathrm{GmbH} \& \mathrm{Co}$ $\mathrm{KG}$; 81:19:0.1, vol/vol/vol) with a $\mathrm{pH}$ of 2.5. Detection of quercetin and its potential metabolites was performed with an electrochemical 4-channel detector (Coul Array 5600A; ESA Biosciences Inc., Chelmsford, MA). Quercetin and quercetin metabolites were identified by comparing the retention times with those of authentic standard substances. Calibration samples were treated the same way as the HGT samples with separate approaches for analysis of quercetin and its metabolites, respectively, and prepared as follows: 750 $\mu \mathrm{L}$ (quercetin analysis) or $800 \mu \mathrm{L}$ (metabolite analysis) of the buffered inoculum used in the HGT (inactivated by cooking of the rumen-fluid sample) was spiked with $200 \mu \mathrm{L}$ of a methanolic stock solution containing different concentrations of quercetin aglycone (Rotichrom HPLC, >99 \% purity; Carl Roth GmbH and Co. KG; methanol: J.T. Baker) or of the 3 metabolites (PG, $\geq 99 \%$ purity; 3,4-DHPAA, $98 \%$ purity; 4-MC, $\geq 95$ $\%$ purity; Sigma Aldrich Chemie $\mathrm{GmbH}$ ), respectively. In addition, $50 \mu \mathrm{L}$ of a methanolic stock solution containing kaempferol (1 mol/L; Rotichrom HPLC, Carl Roth GmbH and Co. KG) as an internal standard were added to all calibration samples. For quantification of quercetin, 3,4-DHPAA and 4-MC chromatograms obtained at $420 \mathrm{mV}$ were used, whereas PG was analyzed 
at $580 \mathrm{mV}$ using the Coul Array Software (Coul Array Data Station 3.00, version 3.10; ESA Biosciences Inc.). Detection limits for quercetin, PG, 3,4-DHPAA, and $4-\mathrm{MC}$ were in the range of $1 \mu \mathrm{mol} / \mathrm{L}$.

\section{VFA Analysis}

Rumen fluid was analyzed for VFA (acetate, propionate, butyrate, isobutyrate, valerate, and isovalerate). Samples were prepared by vacuum distillation as previously described (Zijlstra et al., 1977) with modifications according to Wischer et al. (2013); thawed samples were mixed by stirring and centrifugation $(4.000 \times g$ for $5 \mathrm{~min}$ at $4^{\circ} \mathrm{C}$ ). One milliliter of the supernatant was transferred into an Erlenmeyer flask, $0.1 \mathrm{~mL}$ of internal standard solution $(80 \mathrm{mmol} / \mathrm{L} 2$-methylvaleric acid in $50 \%$ formic acid) was added, and the sample was frozen in an alcohol bath at $-20^{\circ} \mathrm{C}$ under continuous rotation. For vacuum distillation, a glass distribution ring bearing eight 3 -way distilling receivers was connected to a vacuum pump (RZ 16, Vacuubrand, Wertheim, Germany). Each of these receivers was attached to an Erlenmeyer flask containing the frozen sample and a receiving tube. The receiving tubes were immersed in a Dewar vessel containing liquid nitrogen. Vacuum was applied until the samples were completely dry. The distillate was thawed at room temperature, and the samples were analyzed in duplicate using a GC (Hewlett-Packard 6890; Agilent, Waldbronn, Germany) equipped with a flame-ionization detector, an autosampler, and an HP-FFAP fused silica capillary column $(25 \mathrm{~m} \times 0.32 \mathrm{~mm}$, film thickness $0.5 \mu \mathrm{m}$, HP 7683; Agilent). The oven temperature was initially set at $80^{\circ} \mathrm{C}$ isothermal for $1 \mathrm{~min}$, and then increased to $205^{\circ} \mathrm{C}$ by $20^{\circ} \mathrm{C} / \mathrm{min}$ and held at $205^{\circ} \mathrm{C}$ for $2 \mathrm{~min}$. The temperatures of the detector and injector were maintained at $260^{\circ} \mathrm{C}$. The column head pressure of the carrier gas (helium, purity $\geq 99.9 \%$ ), total flow of $62.5 \mathrm{~mL} / \mathrm{min}$, was $227 \mathrm{kPa}$ in constant pressure mode. The injector was operated in split mode at a split ratio of 40:1 and a split flow of $60 \mathrm{~mL} / \mathrm{min}$. The injection volume was $0.1 \mu \mathrm{L}$. The detector gas supply was $40 \mathrm{~mL} / \mathrm{min}$ hydrogen (purity $\geq 99.9 \%$ ), $450 \mathrm{~mL} / \mathrm{min}$ air (free of hydrocarbons), and $45 \mathrm{~mL} / \mathrm{min}$ nitrogen (purity $\geq 99.9 \%$ ). Calibration curves with VFA standards (GC grade; Fluka, Taufkirchen, Germany) were found to be linear within the range of 0.5 to $180 \mathrm{mmol} / \mathrm{L}\left(\mathrm{R}^{2}>0.998\right)$ for all individual VFA included in the analyses. Detection limits were between 2 and $8 \mu \mathrm{mol} / \mathrm{L}$ at a signal-to-noise ratio of 3 .

Additionally, percentages of acetate, propionate, and butyrate relative to total VFA were determined at $2 \mathrm{~h}$ after i.r. application of test substances.

\section{Statistical Analysis}

Data of experiment 1 are presented as mean values with corresponding SEM calculated with GraphPadPrism (version 4.01, GraphPad Software Inc., San Diego, CA). Statistical analysis of gas production data from experiment 2 was conducted using PROC MIXED of SAS (SAS Institute Inc., Version 9.2, Cary, NC). The model included substrate, flavonoid addition, and their interaction as fixed effects. Comparisons of means were performed by the Tukey-Kramer post hoc test. A $P$-value $<0.05$ was considered as significant. Comparisons were made separately for quercetin and rutin supplementation.

Data of experiment 3 are presented as mean values with corresponding SEM calculated using GraphPadPrism. For better characterization of the time course of ruminal concentrations of total VFA (sum of individual VFA), maximum concentration, time to achieve maximum concentration, and the area under the concentration-time curve of total VFA ( $\left.\mathrm{AUC}_{\text {Total }}\right)$ from 0 to $8 \mathrm{~h}$ were determined using GraphPadPrism. For comparison of calculated parameters, an ANOVA with a Bonferroni post hoc test was used. A $P$-value $<0.05$ was considered to be significant. Comparisons were made separately for the application of quercetin aglycone and rutin.

\section{RESULTS}

\section{Experiment 1}

The concentration-time curves of quercetin and its metabolites (PG, 3,4-DHPAA, and 4-MC) during incubation at an initial quercetin concentration of 100 $\mu \mathrm{mol} / \mathrm{L}$ quercetin aglycone as well as the respective concentration-time curve using inactivated rumen fluid as inoculum are presented in Figure 2. During the first $8 \mathrm{~h}$ of incubation, quercetin showed a fast exponential disappearance reaching concentrations in the range of its detection limit $(1 \mu \mathrm{mol}$ quercetin/L) after $24 \mathrm{~h}$. However, when inactivated rumen fluid was used, quercetin concentration only moderately decreased within the first $8 \mathrm{~h}$ of incubation and then remained constant at concentrations of 65 to $80 \mu \mathrm{mol} / \mathrm{L}$. The concentration of quercetin in samples without the addition of quercetin (controls) was always in the range of or below the detection limit (data not shown). Concomitant with the fast disappearance of quercetin, the concentration of 3,4-DHPAA rapidly increased up to the maximum of $34.3 \pm 5.5 \mu \mathrm{mol} / \mathrm{L}$ at $2.5 \mathrm{~h}$ with a subsequent decrease to concentrations below the detection limit (1 $\mu \mathrm{mol} / \mathrm{L}$ ) within the following $5.5 \mathrm{~h}$ of incubation. The 
concentration of 4-MC started to increase after $1.5 \mathrm{~h}$ of incubation, reaching $11.2 \pm 4.7 \mu \mathrm{mol} / \mathrm{L}$ after $8 \mathrm{~h}$ and thereafter decreased constantly to $3.3 \pm 2.0 \mu \mathrm{mol} / \mathrm{L}$ after $24 \mathrm{~h}$. The concentration of PG showed no clear time dependence and was not different from controls without the addition of quercetin (Figure 2). Under control conditions concentrations of the quercetin metabolite PG was 3 to $9 \mu \mathrm{mol} / \mathrm{L}$, respectively, whereas concentrations of 4-MC and 3,4-DHPAA were always below the detection limit during the whole incubation time (results not shown).

\section{Experiment 2}

Total gas and methane production of incubations containing quercetin either applied as aglycone or as rutin are shown in Tables 2 and 3. Neither quercetin nor rutin supplementation influenced gas or methane production in vitro irrespective of the dose applied. Methane concentration (\% of volume) in total gas was slightly higher $(P<0.05)$ with grass hay $(27.1)$ compared with concentrate (25.0) and straw (25.5) but was not affected by quercetin or rutin supplementation. No

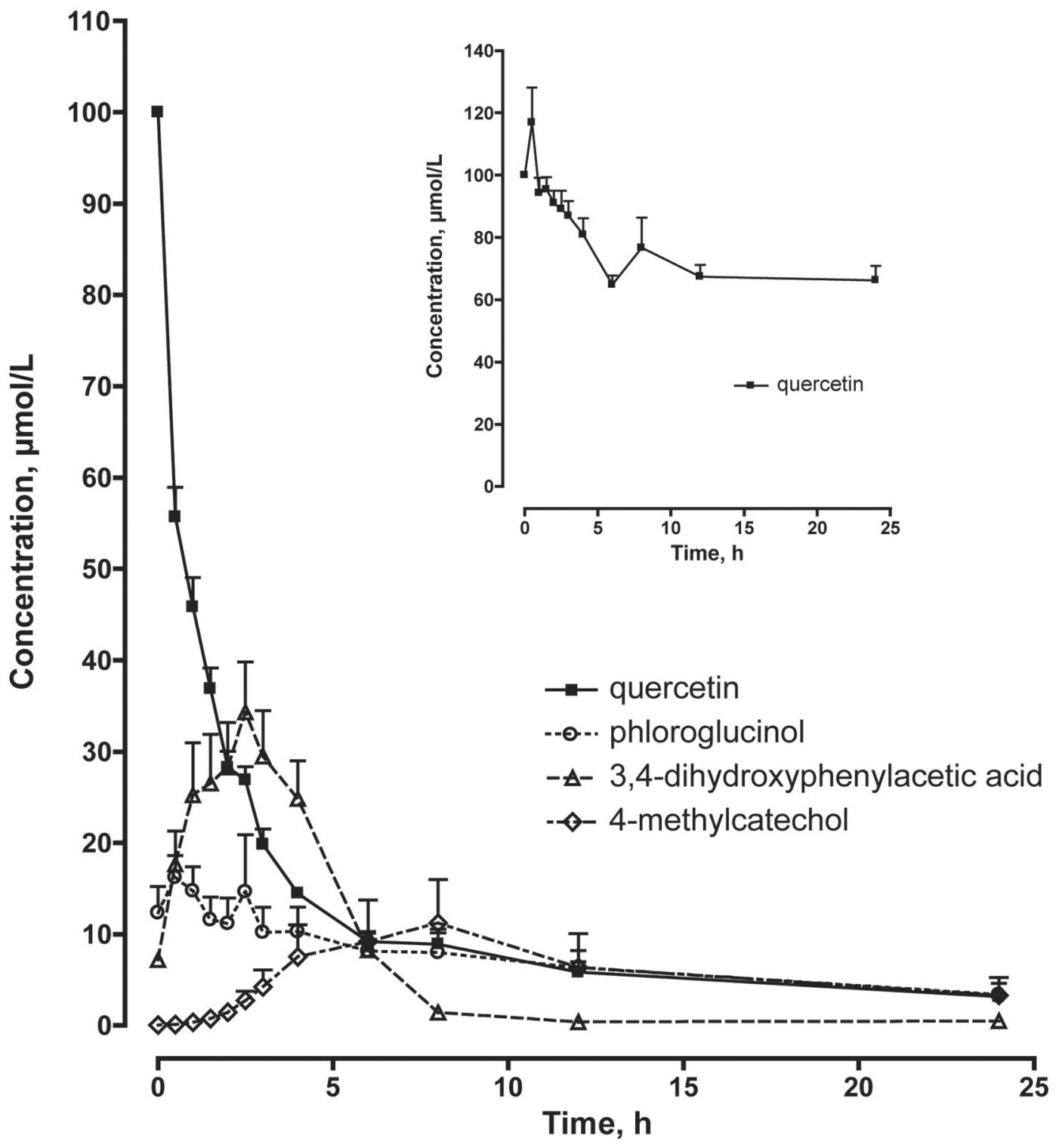

Figure 2. Time course of the concentrations of quercetin and its metabolites phloroglucinol, 3,4-dihydroxyphenylacetic acid, and 4-methylcatechol in inoculum (initial quercetin concentration of 0 or $100 \mu \mathrm{mol} / \mathrm{L}$, respectively). Inset: Time course of quercetin concentrations obtained with inactivated rumen fluid (initial quercetin concentration: $100 \mu \mathrm{mol} / \mathrm{L}$ ). Means $+\mathrm{SEM}, \mathrm{n}=8$ or 4 for active or inactivated rumen fluid, respectively. 
Table 2. Effect of quercetin $(\mu \mathrm{mol} / \mathrm{L})$ on in vitro total gas and methane production $(\mathrm{mL} / 200 \mathrm{mg}$ of substrate) using concentrate, grass hay, and straw as substrate

\begin{tabular}{llcc}
\hline Substrate & Quercetin & $\begin{array}{c}\text { Total } \\
\text { gas }\end{array}$ & Methane \\
\hline Concentrate & 0 & $56.3^{\mathrm{a}}$ & $14.1^{\mathrm{a}}$ \\
& 50 & $56.0^{\mathrm{a}}$ & $14.0^{\mathrm{a}}$ \\
Grass hay & 100 & $56.1^{\mathrm{a}}$ & $14.0^{\mathrm{a}}$ \\
& 0 & $31.4^{\mathrm{b}}$ & $8.4^{\mathrm{b}}$ \\
Straw & 50 & $30.9^{\mathrm{b}}$ & $8.4^{\mathrm{b}}$ \\
& 100 & $31.1^{\mathrm{b}}$ & $8.4^{\mathrm{b}}$ \\
SEM & 0 & $28.9^{\mathrm{c}}$ & $7.3^{\mathrm{c}}$ \\
ANOVA (P-values) & 50 & $28.6^{\mathrm{c}}$ & $7.2^{\mathrm{c}}$ \\
Quercetin & 100 & $28.4^{\mathrm{c}}$ & $7.3^{\mathrm{c}}$ \\
Substrate & & 0.4 & 0.2 \\
Quercetin $\times$ substrate & & 0.5103 & 0.9324 \\
a-c $^{-\mathrm{c}}$ Means within a column $(\mathrm{n}=6 /$ incubation $)$ bearing & no common \\
superscript differ significantly. & \multicolumn{2}{l}{}
\end{tabular}

interactions between quercetin source and substrate on gas and methane production were observed.

\section{Experiment 3}

The concentration-time profile of total VFA after application of physiological saline (control) or of 10 and $50 \mathrm{mg}$ of quercetin equivalents $/ \mathrm{kg}$ of $\mathrm{BW}$ as quercetin aglycone or as rutin, respectively, are presented in Figure 3. Prior to morning feeding (before application of the test compounds), basal concentrations of total VFA were around $61.0 \pm 1.1 \mathrm{mmol} / \mathrm{L}$, increasing to maximum concentrations of $86.0 \pm 8.0$ to $94.8 \pm 9.2$ $\mathrm{mmol} / \mathrm{L}$ after feed intake. Neither the application of quercetin aglycone nor of rutin resulted in changes in the AUC, maximal concentrations of total VFA, and time points of maximal concentration compared with control (Tables 4 and 5).

The molar ratio of individual VFA was also not changed by the application of quercetin and rutin. For all treatments, the dominant VFA was acetate (66$72 \%$ ), followed by propionate (15-20\%) and butyrate (9-11\%), whereas isobutyrate, valerate, and isovalerate were present only in minor amounts $(3 \%)$ of total VFA.

\section{DISCUSSION}

In a preceding study, we investigated the oral bioavailability of the flavonol quercetin in ruminally fistulated cows. These experiments revealed a rather low absolute bioavailability of quercetin especially after application of the quercetin aglycone. The relative bioavailability of quercetin using its glucorhamnoside rutin, however, was
Table 3. Effect of rutin $(\mu \mathrm{mol} / \mathrm{L})$ on in vitro total gas and methane production $(\mathrm{mL} / 200 \mathrm{mg}$ of substrate) using concentrate, grass hay, and straw as substrate

\begin{tabular}{llcc}
\hline Substrate & Rutin & $\begin{array}{c}\text { Total } \\
\text { gas }\end{array}$ & Methane \\
\hline Concentrate & 0 & $56.3^{\mathrm{a}}$ & $14.1^{\mathrm{a}}$ \\
& 50 & $56.5^{\mathrm{a}}$ & $14.1^{\mathrm{a}}$ \\
Grass hay & 100 & $56.3^{\mathrm{a}}$ & $14.1^{\mathrm{a}}$ \\
& 0 & $31.4^{\mathrm{b}}$ & $8.4^{\mathrm{b}}$ \\
Straw & 50 & $31.4^{\mathrm{b}}$ & $8.4^{\mathrm{b}}$ \\
& 100 & $31.5^{\mathrm{b}}$ & $8.5^{\mathrm{b}}$ \\
SEM & 0 & $28.9^{\mathrm{c}}$ & $7.3^{\mathrm{c}}$ \\
ANOVA (P-values) & 50 & $29.0^{\mathrm{c}}$ & $7.3^{\mathrm{c}}$ \\
Rutin & 100 & $29.3^{\mathrm{c}}$ & $7.4^{\mathrm{c}}$ \\
Substrate & & 0.4 & $0.2^{2}$ \\
Rutin $\times$ substrate & & 0.8258 & 0.9243 \\
a-c Means within a column $(\mathrm{n}=6 /$ incubation) bearing & no common \\
superscript differ significantly. &
\end{tabular}

substantially higher (Berger et al., 2012). Therefore, the aims of the present study were to get information about ruminal degradation of quercetin using the HGT. In addition, we investigated possible effects of quercetin on ruminal fermentation, applied either as aglycone or as rutin, in ruminally cannulated cows.

\section{Ruminal Degradation of Quercetin}

Results from the present in vitro experiments show fast and extensive microbial degradation of quercetin aglycone. The breakdown of quercetin and the concomitant appearance of its degradation products 3,4-DHPAA and 4-MC are due to microbial activity rather than spontaneous decomposition of the flavonol because degradation of quercetin was largely prevented when inactivated ruminal fluid was used. With respect to quercetin degradation, similar results from experiments using an in vitro colon-simulation technique with porcine feces as an inoculum have been reported (Cermak and Breves, 2006). Our results also correspond with findings of other studies that have investigated quercetin degradation in feces of different monogastric species (Winter et al., 1989; Braune et al., 2001; Lin et al., 2003), whereby quercetin degradation in our study as well as in the study of Labib et al. (2004) with pigs mainly occurred within 8 to $10 \mathrm{~h}$. In accordance with results from different studies in monogastric species, we could identify 3,4-DHPAA and 4-MC as major metabolites of quercetin (Justesen et al., 2000; Aura et al., 2002; Hein et al., 2008). We speculate that 4-MC is derived from the further breakdown of 3,4-DHPAA because its increase was accompanied by the decrease 
of 3,4-DHPAA (Figure 2). The described metabolites of quercetin (3,4-DHPAA, 4-MC) might affect ruminal microbiota and, thus, fermentation. In this context, Stack et al. (1983; Stack and Cotta, 1986) reported a stimulation of growth of Ruminococcus albus 8 by phenyl acetic acid and phenyl propionic acid. Phloroglucinol, which was described in several studies (Cheng et al., 1969; Winter et al., 1991; Schneider et al., 1999) as a metabolite of the A-ring of quercetin (Figure 1), was also detected in our study. However, this compound could not clearly be specified as a quercetin metabolite in our study because we found no differences between incubations with or without the addition of quercetin. In this context, it should be mentioned that in some studies PG was detected as an intermediate of quercetin degradation, which was further transformed to acetate, butyrate, and $\mathrm{CO}_{2}$ (Simpson et al., 1969; Tsai et al., 1976; Schoefer et al., 2003). Because ruminal degradation of quercetin is very fast, with about $90 \%$ of the initial amount being degraded within $5 \mathrm{~h}$, it can be assumed that higher passage rates of feed as present in high-yielding dairy cows may have only a minor influence on the kinetics of quercetin when orally supplemented as quercetin aglycone.

\section{Influence of Quercetin on Ruminal Fermentation}

In accordance with previous findings concerning the influence of quercetin on different ruminal fermentation parameters (Broudiscou et al., 2000; Bodas et al., 2008; Lourenço et al., 2008), we could only show small or no effects, respectively, of quercetin on concentration of total VFA, the molar ratio of individual VFA, as well as on the kinetics of VFA production. Possible effects of quercetin are of course a question of the quercetin dosage applied but are also related to the residence time of quercetin in the forestomachs. Results of our study indicate fast disappearance of quercetin from the reticulorumen as a combination of bacterial break down and absorption. On the one hand, rapid absorption of quercetin is supported by the finding that maximal plasma concentrations of quercetin and its metabolites occurred very early in cows; that is, within 30 to $42 \mathrm{~min}$ after i.r. quercetin or rutin application, respectively (Berger et al., 2012). On the other hand, as shown in the present work, quercetin is rapidly degraded by ruminal microorganisms.

The findings from our in vivo experiments are supported by the results of the present in vitro experiments, which revealed no influences of quercetin, applied either as aglycone or as rutin, on cumulative gas production using various substrates. As expected, however, total gas and methane production decreased in the order concentrate $>$ grass hay $>$ straw. This results are con-
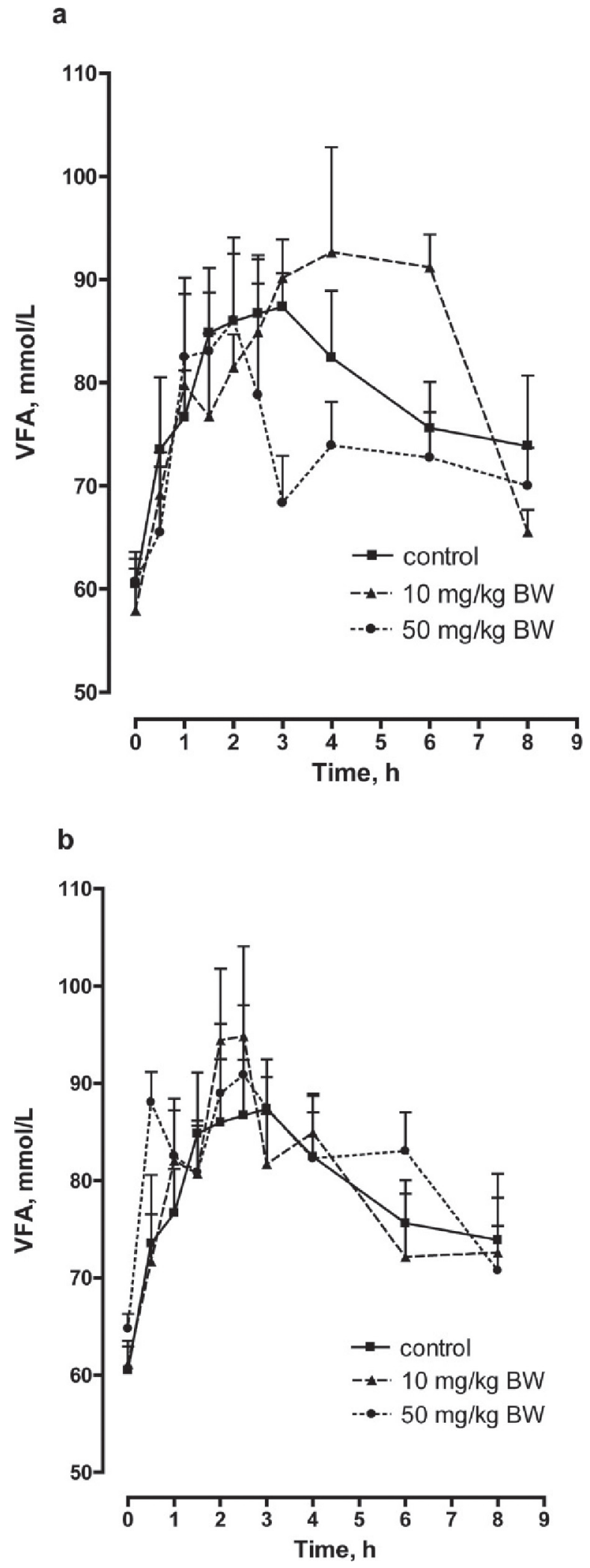

Figure 3. Concentration-time curves of total VFA in the rumen after intraruminal application of physiological saline (control) or 10 or $50 \mathrm{mg}$ of quercetin equivalents $/ \mathrm{kg}$ of BW, respectively, as quercetin aglycone (a) or rutin (b), respectively. Means + SEM, $\mathrm{n}=5$. 
Table 4. Kinetic parameters (mean \pm SEM, $\mathrm{n}=5$ ) of ruminal total VFA production after intraruminal application of physiological saline (control) or $10 \mathrm{or} 50 \mathrm{mg}$ of quercetin equivalents $/ \mathrm{kg}$ of $\mathrm{BW}$ as quercetin aglycone

\begin{tabular}{lccc}
\hline Item $^{1}$ & Control & $10 \mathrm{mg} / \mathrm{kg}$ of BW & $50 \mathrm{mg} / \mathrm{kg}$ of BW \\
\hline $\mathrm{c}_{\max }, \mathrm{mmol} / \mathrm{L}$ & $93.3 \pm 4.9$ & $102.1 \pm 6.2$ & $89.6 \pm 8.0$ \\
$\mathrm{t}_{\max }, \mathrm{h}$ & $2.8 \pm 0.4$ & $3.6 \pm 0.8$ & $3.1 \pm 1.2$ \\
$\mathrm{AUC}_{\text {Total }}, \mathrm{mmol} / \mathrm{L} \times \mathrm{h}$ & $633.2 \pm 33.2$ & $665.1 \pm 34.6$ & $590.8 \pm 33.2$ \\
\hline${ }^{1} \mathrm{c}_{\max }=$ maximal concentration of VFA; $\mathrm{t}_{\max }=$ time point of maximal concentration; & $\mathrm{AUC}_{\text {Total }}=$ area under the \\
curve from 0 to 8 h for total VFA.
\end{tabular}

sistent with the in vitro studies of Klevenhusen et al. (2008) and Navarro-Villa et al. (2011a,b), who found an increase in methane output as the quantity of starch in the diet increased. Such an effect can be largely explained by the increasing amount of fermentable substrate with higher-quality feeds. However, as pointed out by Navarro-Villa et al. (2011a,b), when expressed relative to feed that disappeared or was fermented, the effect on methane production is reversed, reflecting the greater digestibility of concentrate. Different from our findings, however, Broudiscou et al. (2000, 2002) reported an inhibition of degradation of NDF and ADF when an isoquercitrin-containing extract of Equisetum arvense was incubated with a mixture of grass hay and concentrate (50:50). Furthermore, gas production $\left(\mathrm{CO}_{2}\right.$ and $\mathrm{CH}_{4}$ ) was reduced, which was accompanied by an increased production of propionate and $\mathrm{H}_{2}$ (Broudiscou et al., 2000, 2002). In a further study, where hay was used as a substrate, Broudiscou and Lassalas (2000) found a stimulation of fermentation processes with increased production of acetate and butyrate by $E q$ uisetum arvense as well as by isoquercitrin, whereas gas production was not influenced. It has to be kept in mind, however, that effects caused using quercetincontaining plant extracts cannot be clearly attributed to a particular compound because of their variable and not clearly defined polyphenolic content. Nevertheless, Lourenço et al. (2008) and Leiber et al. (2012) showed an increase of VFA concentration even with the pure forms of quercetin and rutin. Thus, Leiber et al. (2012), who also used hay as substrate, showed that the addition of rutin $(5$ and $500 \mu \mathrm{mol}$ of quercetin equivalents/L) led to a stimulation of gas production whereby the proportion of $\mathrm{CH}_{4}$ production decreased relative to $\mathrm{CO}_{2}$ production. Leiber et al. (2012) assumed that rutin was used as substrate for nonmethanogenic microbes, which resulted in the increase of $\mathrm{CO}_{2}$ production and, thus, lowered the proportion of $\mathrm{CH}_{4}$. Incubation of buckwheat with hay in the same study led to a decrease of VFA concentration as well as gas production. In the latter case, ratio of $\mathrm{CH}_{4}$ to $\mathrm{CO}_{2}$ was lowered, as well as absolute $\mathrm{CH}_{4}$ production.

\section{CONCLUSIONS}

The results of the present study show that quercetin is subjected to fast and extensive degradation by ruminal microbiota. This result provides an explanation for low bioavailability of quercetin in cows after i.r. application. Furthermore, quercetin (and rutin) did not affect ruminal fermentation processes and thus can be considered harmless, at least at the concentrations used in the present study. A targeted application of quercetin in ruminants, however, will only be meaningful if clear effects on performance and health of animals can be demonstrated.

\section{ACKNOWLEDGMENTS}

This work was financially supported by the Federal Ministry of Education and Research (Berlin, Germany; grant no. 0315538A). The authors are grateful to the Institute of Animal Nutrition of the University of Hohenheim (Stuttgart, Germany) for analysis of VFA in rumen samples and Wiebke Kühl (Institute of Animal Nutrition and Physiology, Christian-Albrechts-Univer-

Table 5. Kinetic parameters (mean \pm SEM, $\mathrm{n}=5$ ) of ruminal total VFA production after intraruminal application of physiological saline (control) or $10 \mathrm{or} 50 \mathrm{mg}$ of quercetin equivalents $/ \mathrm{kg}$ of BW as rutin

\begin{tabular}{lccc}
\hline Item $^{1}$ & Control & $10 \mathrm{mg} / \mathrm{kg}$ of BW & $50 \mathrm{mg} / \mathrm{kg}$ of BW \\
\hline $\mathrm{c}_{\max }, \mathrm{mmol} / \mathrm{L}$ & $93.3 \pm 4.9$ & $98.8 \pm 8.3$ & $99.4 \pm 4.4$ \\
$\mathrm{t}_{\max }, \mathrm{h}$ & $2.8 \pm 0.4$ & $2.6 \pm 0.4$ & $2.9 \pm 0.8$ \\
$\mathrm{AUC}$ & $633.2 \pm 33.2$ & $632.7 \pm 27.3$ & $657.6 \pm 22.8$ \\
\hline${ }_{\text {Total }}, \mathrm{mmol} / \mathrm{L} \times \mathrm{h}$ & ${ }^{\mathrm{c}}$ max \\
curve from 0 to 8 $\mathrm{h}$ for total VFA.
\end{tabular}
curve from 0 to $8 \mathrm{~h}$ for total VFA. 
sity Kiel, Germany) for excellent technical assistance in sample preparation.

\section{REFERENCES}

Ader, P., A. Wessmann, and S. Wolffram. 2000. Bioavailability and metabolism of the flavonol quercetin in the pig. Free Radic. Biol. Med. 28:1056-1067.

Amelchanka, S. L., M. Kreuzer, and F. Leiber. 2010. Utility of buckwheat (Fagopyrum esculentum Moench) as feed: Effects of forage and grain on in vitro ruminal fermentation and performance of dairy cows. Anim. Feed Sci. Technol. 155:111-121.

Aura, A. M., K. A. O'Leary, G. Williamson, M. Ojala, M. Bailey, R. Puupponen-Pimiä, A. M. Nuutila, K. M. Oksman-Caldentey, and K. Poutanen. 2002. Quercetin derivatives are deconjugated and converted to hydroxyphenylacetic acids but not methylated by human fecal flora in vitro. J. Agric. Food Chem. 50:1725-1730.

Berger, L. M., S. Wein, R. Blank, C. C. Metges, and S. Wolffram. 2012. Bioavailability of the flavonol quercetin in cows after intraruminal application of quercetin aglycone and rutin. J. Dairy Sci. 95:5047-5055.

Besle, J. M., D. Viala, B. Martin, P. Pradel, B. Meunier, J. L. Berdagué, D. Fraisse, J. L. Lamaison, and J. B. Coulon. 2010. Ultraviolet-absorbing compounds in milk are related to forage polyphenols. J. Dairy Sci. 93:2846-2856.

Bodas, R., S. López, M. Fernández, R. García-González, A. B. Rodríguez, R. J. Wallace, and J. S. González. 2008. In vitro screening of the potential of numerous plant species as antimethanogenic feed additives for ruminants. Anim. Feed Sci. Technol. 145:245-258.

Braune, A., M. Gutschow, W. Engst, and M. Blaut. 2001. Degradation of quercetin and luteolin by Eubacterium ramulus. Appl. Environ. Microbiol. 67:5558-5567.

Broudiscou, L.-P., and B. Lassalas. 2000. Effects of Lavandula officinalis and Equisetum arvense dry extracts and isoquercitrin on the fermentation of diets varying in forage contents by rumen microorganisms in batch culture. Reprod. Nutr. Dev. 40:431-440.

Broudiscou, L.-P., Y. Papon, and A. F. Broudiscou. 2000. Effects of dry plant extracts on fermentation and methanogenesis in continuous culture of rumen microbes. Anim. Feed Sci. Technol. 87:263-277.

Broudiscou, L.-P., Y. Papon, and A. F. Broudiscou. 2002. Effects of dry plant extracts on feed degradation and the production of rumen microbial biomass in a dual outflow fermenter. Anim. Feed Sci. Technol. 101:183-189.

Cermak, R., and G. Breves. 2006. In vitro degradation of the flavonol quercetin and of quercetin glycosides in the porcine hindgut. Arch. Anim. Nutr. 60:180-189.

Cermak, R., S. Landgraf, and S. Wolffram. 2003. The bioavailability of quercetin in pigs depends on the glycoside moiety and on dietary factors. J. Nutr. 133:2802-2807.

Chen, X., O. Q. P. Yin, Z. Zuo, and M. S. S. Chow. 2005. Pharmacokinetics and modeling of quercetin and metabolites. Pharm. Res. 22:892-901.

Cheng, K.-J., G. A. Jones, F. J. Simpson, and M. P. Bryant. 1969. Isolation and identification of rumen bacteria capable of anaerobic rutin degradation. Can. J. Microbiol. 15:1365-1371.

Erlund, I. 2004. Review of the flavonoids quercetin, hesperetin, and naringenin. Dietary sources, bioactivities, bioavailability, and epidemiology. Nutr. Res. 24:851-874.

Fraisse, D., A. Carnat, D. Viala, P. Pradel, J. M. Besle, J. P. Coulon, C. Felgines, and J. L. Lamaison. 2007. Polyphenolic composition of a permanent pasture: Variations related to the period of harvesting. J. Sci. Food Agric. 87:2427-2435.

Gohlke, A., C. J. Ingelmann, A. Starke, S. Wolffram, and C. C. Metges. 2013. Bioavailability of quercetin from its aglycone and its glucorhamnoside rutin in lactating dairy cows after duodenal administration. J. Dairy Sci. 96:2303-2313.

Hein, E. M., K. Rose, G. van't Slot, A. W. Friedrich, and H. U. Humpf. 2008. Deconjugation and degradation of flavonol glycosides by pig cecal microbiota characterized by fluorescence in situ hybridization (FISH). J. Agric. Food Chem. 56:2281-2290.

Justesen, U., E. Arrigoni, B. R. Larsen, and R. Amado. 2000. Degradation of flavonoid glycosides and aglycones during in vitro fermentation with human faecal flora. LWT Food Sci. Technol. $33: 424-430$.

Kehrli, M. E., J. D. Neill, C. Burvenich, J. P. Goff, J. D. Lippolis, T. A. Reinhardt, and B. J. Nonnecke. 2006. Energy and protein effects on the immune system. Pages 455-471 in Ruminant Physiology. Digestion, Metabolism and Impact of Nutrition on Gene Expression, Immunology and Stress. K. Sejrsen, T. Hvelplund, and M. O. Nielsen, ed. Wageningen Acad. Publ., Wageningen, the Netherlands.

Klevenhusen, F., S. M. Bernasconi, M. Kreuzer, and C. R. Soliva. 2008. The methanogenic potential and C-isotope fractionation of different diet types represented by either $\mathrm{C} 3$ or $\mathrm{C} 4$ plants as evaluated in vitro and in dairy cows. Aust. J. Exp. Agric. 48:119-123.

Krishnamurty, H. G., K.-J. Cheng, G. A. Jones, F. J. Simpson, and J E. Watkin. 1970. Identification of products produced by the anaerobic degradation of rutin and related flavonoids by Butyrivibrio sp. C3. Can. J. Microbiol. 16:759-767.

Labib, S., A. Erb, M. Kraus, T. Wickert, and E. Richling. 2004. The pig caecum model: A suitable tool to study the intestinal metabolism of flavonoids. Mol. Nutr. Food Res. 48:326-332.

Leiber, F., C. Kunz, and M. Kreuzer. 2012. Influence of different morphological parts of buckwheat (Fagopyrum esculentum) and its major secondary metabolite rutin on rumen fermentation in vitro. Czech J. Anim. Sci. 57:10-18.

Lin, Y., S. Hsiu, Y. Hou, H. Chen, and P. Chao. 2003. Degradation of flavonoid aglycones by rabbit, rat and human fecal flora. Biol. Pharm. Bull. 26:747-751.

Lorz, A., and E. Metzger. 2008. Tierschutzgesetz: Tierschutzgesetz mit Allgemeiner Verwaltungsvorschrift, Rechtsverordnungen und Europäische Übereinkommen; Kommentar. C. H. Beck Verlag, München, Germany.

Lourenço, M., P. W. Cardozo, S. Calsamiglia, and V. Fievez. 2008. Effects of saponins, quercetin, eugenol, and cinnamaldehyde on fatty acid biohydrogenation of forage polyunsaturated fatty acids in dual-flow continuous culture fermenters. J. Anim. Sci. 86:30453053.

Menke, K. H., L. Raab, A. Salewski, H. Steingass, D. Fritz, and W. Schneider. 1979. The estimation of the digestibility and metabolizable energy content of ruminant feeding stuffs from the gas production when they are incubated with rumen liquor in vitro. J. Agric. Sci. 93:217-222.

Menke, K. H., and H. Steingass. 1988. Estimation of the energetic feed value obtained from chemical analysis and in vitro gas production using rumen fluid. Anim. Health Res. Rev. 28:7-55.

Mertens, D. R. 2002. Gravimetric determination of amylase-treated neutral detergent fibre in feeds with refluxing beakers or crucibles: Collaborative study. J. AOAC Int. 85:1217-1240.

Middleton, E., C. Kandaswami, and T. C. Theoharides. 2000. The effects of plant flavonoids on mammalian cells: Implications for inflammation, heart disease, and cancer. Pharmacol. Rev. 52:673751

Navarro-Villa, A., M. O'Brien, S. Lopez, T. M. Boland, and P. O'Kiely. 2011a. In vitro rumen methane output of red clover and perennial ryegrass assayed using the gas production technique (GPT). Anim. Feed Sci. Technol. 168:152-164.

Navarro-Villa, A., M. O'Brien, S. Lopez, T. M. Boland, and P. O'Kiely. 2011b. Modifications of a gas production technique for assessing in vitro rumen methane production from feedstuffs. Anim. Feed Sci. Technol. 166-167:163-174.

Rechner, A. R., M. A. Smith, G. Kuhnle, G. R. Gibson, E. S. Debnam, S. K. Srai, K. P. Moore, and C. A. Rice-Evans. 2004. Colonic metabolism of dietary polyphenols: influence of structure on microbial fermentation products. Free Radic. Biol. Med. 36:212-225.

Schneider, H., A. Schwiertz, M. D. Collins, and M. Blaut. 1999. Anaerobic transformation of quercetin-3-glucoside by bacteria from the human intestinal tract. Arch. Microbiol. 171:81-91. 
Schoefer, L., R. Mohan, A. Schwiertz, A. Braune, and M. Blaut. 2003. Anaerobic degradation of flavonoids by Clostridium orbiscindens. Appl. Environ. Microbiol. 69:5849-5854.

Simpson, F. J., G. A. Jones, and E. A. Wolin. 1969. Anaerobic degradation of some bioflavonoids by microflora of the rumen. Can. J. Microbiol. 15:972-974.

Stack, R. J., and M. A. Cotta. 1986. Effect of 3-phenylpropanoic acid on growth of and cellulose utilization by cellulolytic ruminal bacteria. Appl. Environ. Microbiol. 52:209-210.

Stack, R. J., R. E. Hungate, and W. P. Opsahl. 1983. Phenylacetic acid stimulation of cellulose digestion by Ruminococcus albus 8 . Appl. Environ. Microbiol. 46:539-544.

Stoldt, A.-K., M. Derno, G. Nürnberg, J. M. Weitzel, W. Otten, A. Starke, S. Wolffram, and C. C. Metges. 2015. Effects of a 6 wk intraduodenal supplementation with quercetin on energy metabolism and indicators of liver damage in periparturient dairy cows. J. Dairy Sci. In press

Tsai, C. G., D. M. Gates, W. M. Ingledew, and G. A. Jones. 1976. Products of anaerobic phloroglucinol degradation by Coprococcus sp. Pe15. Can. J. Microbiol. 22:159-164.

USDA. 2011. USDA database for the flavonoid content of selected foods-Release 3. Accessed Nov. 2012. http://www.ars.usda.gov/ SP2UserFiles/Place/12354500/Data/Flav/Flav_R03.pdf.
VDLUFA. 2007. Verband Deutscher Landwirtschaftlicher Untersuchungs- und Forschungsanstalten. Handbuch der Landwirtschaftlichen Versuchs- und Untersuchungsmethodik (VDLUFA-Methodenbuch), Bd. III. Die Chemische Untersuchung von Futtermitteln. VDLUFA-Verlag, Darmstadt, Germany.

Wein, S., and S. Wolffram. 2013. Oral bioavailability of quercetin in horses. J. Equine Vet. Sci. 33:441-445.

Winter, J., L. H. Moore, V. R. Jr. Dowell, and V. D. Bokkenheuser. 1989. C-ring cleavage of flavonoids by human intestinal bacteria. Appl. Environ. Microbiol. 55:1203-1208.

Winter, J., M. R. Popoff, P. Grimont, and V. D. Bokkenheuser. 1991. Clostridium orbiscindens sp. nov., a human intestinal bacterium capable of cleaving the flavonoid C-ring. Int. J. Syst. Bacteriol 41:355-357.

Wischer, G., J. Boguhn, H. Steingaß, M. Schollenberger, K. Hartung, and M. Rodehutscord. 2013. Effect of monensin on in vitro fermentation of silages and microbial protein synthesis. Arch. Anim. Nutr. 67:219-234.

Zijlstra, J. B., J. Beukema, B. G. Wolthers, B. M. Byrne, A. Groen, and J. Dankert. 1977. Pretreatment methods prior to gas chromatographic analysis of volatile fatty acids from faecal samples. Clin. Chim. Acta 78:243-250. 